\title{
Corrigendum: The poetics of peace: From aesthetic knowledge to reconciliation
}

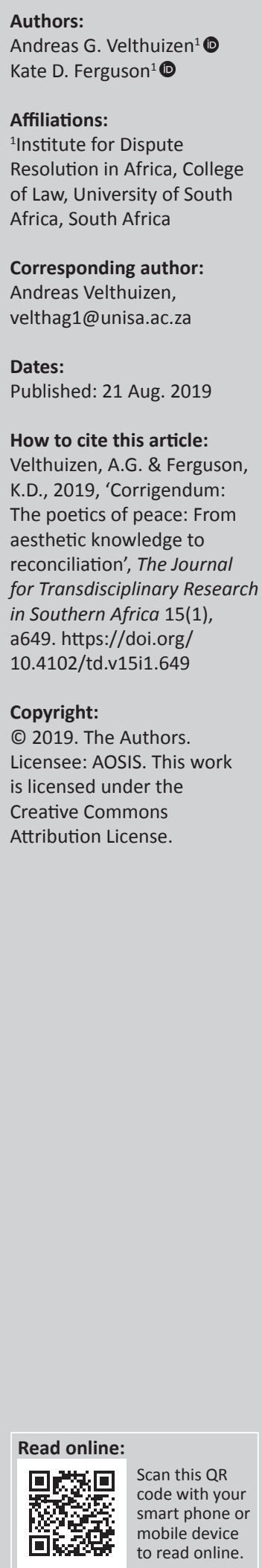

Scan this QR code with your smart phone or mobile device to read online.

In the version of this article initially published, reference was incorrectly made to an interview held with Pupa Jan Pieterse (p. 6). The interview was held with Oupa Jan. The published statement in the article is hereby updated and corrected as follows: 'An interview with Oupa Jan, a community elder, mediator and spiritual leader, revealed that dance is typically initiated to resolve a physical or social ill that needs to be healed in a multidimensional way'.

This correction does not alter the study's findings of significance or overall interpretation of the study results. The authors apologise for any inconvenience caused. 


\section{The poetics of peace: From aesthetic knowledge to reconciliation}

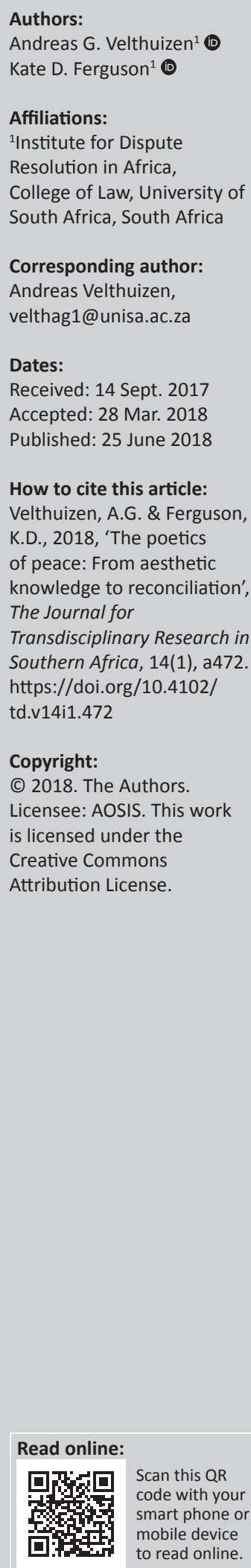

\begin{abstract}
This article is inspired by the need for research methods that would discover the interrelationships of reconciliation and culture, specifically analysing the behaviour of field researchers originating from different lifestyles or culture, observing and participating in the artful expressions of research subjects. The purpose of this article was to present an overview of research into poetics as a source of information that contributes to existing bodies of knowledge and the finding of practical solutions related to peace-building in African communities. The authors argued that knowledge could be discovered from various forms of poetics through sensuous participation and intellectual interpretation and could be applied to the process of reconciliation. In support of this argument, the research was conducted with the San, the First People of southern Africa, in the context of a broader research project that aims at finding and publishing theory for dispute resolution in Africa. The discussion contains a conceptual framework of philosophy and theories that elucidates the concepts of poetics, the aesthetic domain and its relevance to peace and reconciliation in Africa. The transdisciplinary research methodology borrows from ethnographic methodologies including sensuous scholarship and participant observation of ritualistic experiences. The authors conclude that the creative, ritualistic and artistic lifeworlds of communities, in or recovering from conflict situations, are deeply relevant to any real motion towards reconciliation and healing.
\end{abstract}

\section{Introduction}

This article is inspired by the need to discover knowledge in the aesthetic domain of the African episteme. Currently, some African communities are in the process of achieving peaceful reconciliation after being exposed to slavery, colonisation, socio-economic neglect, political marginalisation and violent conflicts. In a world dominated by Western knowledge systems, people in Africa require the capacity to access customary knowledge to understand disputes around them and find solutions to reconciliation. Such customary knowledge can mostly be found in poetic expressions in their own languages. In many cases, the people of Africa became accustomed to the formal articulation of knowledge in languages that were brought by colonisation, such as by the English and French. In those cases, people from communities seldom use the same language they use in their communities to express themselves outside the community. However, the 'language' of music, song, dance and many art forms became a way of disseminating worldviews. For scholarly observers, the challenge is to access the knowledge hidden in an aesthetic domain.

Against this background, the following question arises: how can information from the aesthetic knowledge domain in Africa be accessed and applied for reconciliation in Africa? The purpose of this article is therefore to determine a methodology to access information in the aesthetic knowledge domain in Africa and apply that knowledge, together with other knowledge claims, to find practical solutions for communities in conflict. The analysis will focus on African communities, the building blocks for reconciliation in African society.

The authors argue that if the poetic creation, processes and products (storytelling, art, ritual, music, dance forms, song and poetry) of relatively peaceful communities are discovered, analysed and understood, it will reveal how relationships are reconciled across socially-constructed divisions in communities. It was found that knowledge obtained from the aesthetic domain can contribute to peace strategies in communities and even replace dominant and hegemonic narratives from knowledge systems outside the community. This argument is supported by literature study, field research as well as transdisciplinary, critical and complementary reflection with research participants. In support of the argument, the research was conducted with the San, the First People of southern Africa, in the context of a broader research project that aims at finding 
and publishing theory for dispute resolution in Africa that is engaged in African communities and grounded in African epistemology.

The discussion contains a conceptual framework of philosophy and theories that elucidates the concepts of poetics, the aesthetic domain and its relevance to peace and reconciliation. The research methodology will be explained with specific reference to research carried out during 2016 with the San. Finally, an evaluation of the applicability of knowledge from the aesthetic domain to accomplish peace in Africa is presented.

\section{Conceptual framework}

\section{Reconciliation}

According to Komesaroff, the concept 'reconciliation' is found in all traditions of thought. The Indian culture, for instance, has a hermeneutical approach to reconciliation, meaning dialogue with the self-interpretive skills through selfpurification, abstinence, fasting, meditation and pilgrimage. In the Buddhist tradition, mindset, heart, soul, subjectivity and objectivity are fused into one whole and all phenomena are interconnected and interdependent as a condition of 'Enlightenment' (Komesaroff 2008:1). The Western perspective asserts that conflicts are the consequence of distorted communication, misunderstandings, lack of comprehension, insincerity and deception. Reconciliation is a process of communication 'across difficult, unpredictable, ambiguous and fragile barriers'. To overcome these barriers, in the Western perspective, a 'fusion of horizons' and an open discourse is required, where assumptions are shared, subjectivities are integrated and communication structures are free from coercion and distortion (Habermas 2003:35-38).

According to the African way, reconciliation refers to the traditional African concept described as the spirit of Ubuntu (in Nguni languages), Botho (in Sesotho, Setswana and Tsephedi), Kparakpor (in the Yoruba language) and Ujaama (in Swahili). This concept holds that one's health and wealth is intricately connected to the health and wealth of a greater community, of a greater whole (Velthuizen 2016). Desmond Tutu summarises this as follows: 'Reconciliation is about the healing of breaches, redressing imbalances, the restoration of broken relationships, and the rehabilitation of victim and perpetrator' (Tutu 2000:54-55).

Reconciliation is also broader than just conflict resolution. According to Komesaroff, reconciliation includes the values of peace, justice, fairness, healing and forgiveness, transcending many disciplines such as social, cultural and legal aspirations including human rights, the quest for social justice and coexistence. Furthermore, reconciliation seeks the revival of cultural identity, trust building and rising above personal animosities. Moreover, reconciliation encompasses understanding of and responding to relationships within and between communities as well as cultural, religious and other sensitivities that impede social dialogue. 'At its core, reconciliation is concerned with bringing diverse voices into conversation and balances the perspectives they present' (Komesaroff 2008:10).

\section{Cohen (1997) states that:}

Reconciliation refers to the re-creation and/or creation of the moral framework of a relationship through which individuals and groups overcome alienation by engaging in transformative processes that in themselves embody the norms of respect and fairness intended for their new relationship. Through the ongoing processes of reconciliation, the parties to conflict become increasingly trusting and trustworthy as they understand each other's suffering, acknowledge injustices, and strive to address both unresolved and emerging conflicts in ways that meet their underlying needs. (p. 283)

This is when the contrast between goal-driven, conscious decision-making needed for the survival of individuals and the knowledge required for the survival of the group that resides in the 'non-conscious' realms of the human mind becomes evident (Bateson 1972:147). In the case of reconciliation following civil wars, an evolutionarily and emotionally driven pattern without rational purpose transforms aggression into empathy and desire for revenge into desire for affiliation (Longe \& Brecke 2003:28). Sense-making focuses on discontinuities that an individual experiences when encountering a 'gap' and is compelled to stop and discover a next step. It is about what an individual experiences at that moment, the person's perspective of the fissure, the decision to try to overcome it and progress after the fissure is crossed (Dervin 1992).

We need to find a way to help people be tolerant of the fact that other people see the world differently and that not all differences between human beings need to be resolved (unless we're going to call human life war). (Dervin 2011:61-84)

From the above assertions, it is inferred that reconciliation is first of all personal reconciliation, meaning that the victim, the perpetrator and the affected person first need to find remorse and inner peace as a result of self-knowledge, and then take personal responsibility for the reconciliation process. A personal commitment to the process of reconciliation means that a person assumes responsibility for dialogue aimed at the restoration of peaceful relations characterised by relinquished animosities, recognition of mutual humanity, trust, forgiveness and healing. Furthermore, sense-making is achieved when individuals can cross or close the gaps between themselves and others to become part of a collective awareness of the need for reconciliation. In this process of reconciliation, it is inevitable that social justice, social equilibrium and cultural identity are promoted. However, reconciliation and restoration is seldom a rational process that leads to ideal solutions. Reconciliation evolves from emotions that are deeply imbedded in a subconscious realm of human minds that needs to be accessed and shared to make reconciliation possible.

\section{The aesthetic knowledge domain}

In his classic work Poetics, as translated by Butcher (1992:7), Aristotle identifies persons who, 'by conscious art or 
mere habit, imitate and represent various objects through the medium of colour, form and voice, producing rhythm, language or harmony'. For epistemological, psychological, logical and metaphysical questions to be answered, 18thcentury philosophers such as Edmund Burke and David Hume explained aesthetic concepts empirically by connecting them with individual experiences (physical and psychological) of objects and events, finding objectivity in personal reactions.

Immanuel Kant maintained that aesthetic concepts are essentially subjective (rooted in personal feelings), but conceded that they contain objectivity because personal feelings are general responses to aesthetic objects and events. Emanating from the philosophy of Burke, the human faculty of taste (the ability to discern between what is beautiful and what is ugly) established an epistemological or logical uniqueness for aesthetic concepts. Although there are no aesthetic rules, aesthetic concepts play a significant role in discussions and disputes, being context-dependent, constructed out of social customs. For example, the term 'harmony' may not have the same meaning in different cultures (Eaton 2016).

Edmund Burke in his work Sublime and Beautiful explains that the 'sublime and beautiful' do not come from objects but from objects as they are experienced: the same object can be described as 'fearful' or 'sublime' depending on the situation of the viewer. Burke asserted that aesthetic concepts depend on 'psychophysical machinery' to experience the world, which means that two counterintuitive aesthetic forces need to reconcile: the belief that aesthetic concepts are subjective ('beauty is in the eye of the beholder') and the view that aesthetic concepts are objective ('the sunset or mountains are beautiful'). Aesthetic properties to describe and evaluate aesthetic objects and events are artistic. Burke further warned that taste is not a separate faculty of the mind, distinct from judgement and imagination (Burke 1958:26-27). Russel contrasted science and art by saying that in the study of art we focus primarily on the achievements of the past and neglect those of the present. Science is required for progress, whereas good art demands creativity as a product of individual genius (Russel 1913:390-397).

The importance of discovering meaning by interpretation in social contexts is professed by Heidegger (1927[1962]). The understanding of conditions, in which phenomena are observed, is a stepping stone towards full understanding. All that a person needs is a secure vantage point as foothold. Such a vantage point is established through self-reflection, a consciousness of the position of people in the world, including the essence of their belief system, as well as the importance of cultural and historical context. Furthermore, the hermeneutic cycle described by Heidegger explains the crossing of boundaries in listening to messages, interpreting it and passing it on to others. When other people are exposed to these experiences through discovery, it assists the understanding of the other people. However, it is the fusion of horizons, described by Gadamer (1976:98-99), as the mediation between the immediate horizon of the interpreter and a new emerging horizon, which is the main achievement of complementary reflection.
The explanation of Cohen and Yalen (2005:1-5) asserts that: the aesthetic experience is 'a profound and pleasurable transaction between a human being and certain cultural and artistic forms' arising from the arrangement of the elements of the art form and the perception of the person who experiences it. Aesthetic experience emerges from art forms such as painting on a canvas, reading a novel, embroidering a scarf, watching a dance performance, participating in a drumming ceremony, interface with folk expressions and rituals, or assuming the role of a creator, a composer, an audience, a participant or a performer. Therefore, the aesthetic experience is a powerful resource of learning or reconciliation. In aesthetic experiences between a human being and a natural form, the perceiver may experience strong focus and meditation that are critical for reconciliation, especially to learn the capacity to restore relationships. However, rational processes alone cannot transform relationships. Learning for reconciliation has to take place in body, spirit and mind, restoring damage caused by the trauma of violence. An integration of the sensory and cognitive faculties of a person who engages with artistic and cultural forms within a specific space or time mediates the tensions between order and chaos, tradition and innovation, and the individual and the collective. Reconciliation can manifest when people will acknowledge harms, tell truths, mourn losses and imagine a new future.

Our senses are of social nature, advancing our comprehension of selfhood, culture and social relations. Therefore, sensory scholarship in the fields of sociology, anthropology, history and geography, among others, proliferated into a model that prescribes that both 'semiotics' (meaning making) and 'phenomenological ventures' (i.e. the structures of consciousness as experienced from the vantage point of a person) represent a 'sensory interpretation model'. A cultural system and hierarchy of the senses emerge beyond the hegemony of vision, where sensorial experiences such as the 'feeling in the body' can be sensorially relevant (Low 2012:271).

In her later work, Cohen (2005:51-54) discovered that judgements on aesthetic forms from an aesthetic perspective are authentic judgements that can lead to inferences, important questions and debates on the features of an object or event by several people investigating the form or event. In this kind of investigation, 'supervenience' is applied, meaning that a stable set of properties of an object or event is not required, but the aesthetic experiences are sensory and cognitive. If applied to reconciliation, sensory experience combined with cognition can help former enemies to reconcile, developing a more intricate but refined understanding of their own narratives. An understanding of their own narratives can help communities to address injustices by visualising and giving substance to more equitable relationships. Cohen recommends that policymakers working on rebuilding communities after violence and long-standing oppression should recognise that the arts and cultural work are important resources for coexistence and reconciliation. 
According to Eaton (2016), concepts are determined by language shaped by interests and attitudes that are culturally specific. For instance, African art cannot be described in English without making it English art, and vice versa. Even a concept such as rhythm does not migrate from Europe to Africa without significant modification. Aesthetic concepts are determined culturally, and understanding any particular concept will demand thorough knowledge of the culture in which it functions. According to Eaton, there is no universal concept.

Although this article does not necessarily endorse the notion that there is no universal concept, the authors integrate into their narrative that gender, class, religion and economic or political status often affect the formation and application of aesthetic concepts. These concepts are learnt in the context of the performer, creator, audience, critic, tourist and other observers. Roles are culture-bound, and in some communities they do not even exist. Aesthetic responses may seem 'natural' (e.g. appreciating the sunset), but many responses are subject to social prescription and exclusion.

Bateson (1972:84-85) believes that the way of analysing a system in one milieu can be used to analyse a similar system in another setting. In such analysis, the 'feel' of culture and new thinking is more important than defining scientific concepts in terms of operations to determine or prove them. However, by letting our ideas 'run wild' without formal thought and clarification, we will probably fail to understand what we are experiencing. A combination of loose and strict thinking is 'the most precious tool of science'.

In this regard, Bateson (1972:205-211) warns against the limitations of imagining. The observer cannot imagine the world as it is without making the imagination self-validating. Aesthetic consciousness should be analysed, mapped and synthesised so that it is not just 'fancy creations' from the mind. For instance, the relationship between beauty, ugliness, what is deemed sacred and a specific consciousness should be mapped. The point of interpreting poetics is to keep the interpretation grounded in self-awareness and self-conscious participation, to prevent premature closure on thinking and to encourage creativity in research and findings that reaches for many voices, interaction and intellectual harmony (Brady 1991:12).

Proposing a movement away from positivist paradigms to 'artful-science' through fieldwork, Brady (2003:3-4) identified a new paradigm that requires 'self-conscious knowledge about ordinary realities' in a 'semiotic world' meaning the study of signs and symbols and their use or interpretation together with positivist research. 'No science is an island and no discipline is unconnected to the study of being human'. 'Privileged observation' has merits, but there is no monopoly on truth, irrespective of discipline. Language renders meaning unlimited and responsible social science should reject dogmatic empiricism. Note the words of Shaun McNiff (2008:34) from the art-based research (ABR) method:
'Science tends to reduce experience to core principles while art amplifies and expands, and I see the two as complementary within the total complex of knowing'.

\section{The transdisciplinary nature of knowledge in the aesthetic knowledge domain}

Nicolescu (2005:7) proposes a transdisciplinary methodology that establishes links between persons, facts, images, representations, fields of knowledge and actions to discover the 'Eros of learning'. During the entire lifetime of a person, the integration of beings and phenomena is questioned. Transdisciplinarity articulates among different realities where the flow of information appears to be transmitted in a coherent manner from one reality to another in our physical universe. In order to implement such a methodology, Stoller (2012) proposes the use of sensuous scholarship that links analytical and sensible approaches, which is only possible with the rejection of mind-body duality and acceptance of interconnectedness.

Sensory data are articulated through language and brief sensorial reflections of the researcher while conducting sensual research. In narrative interviews, participant observation and visual methods, sensory research requires innovative sensorial strategies on the part of field researcher. The senses in social life and social interaction may be tapped into for data, implying that the researcher is not neutral, but a participating observer, embroiled in the process as an embodied researcher, collaborating together with the respondent who equally takes on an embodied position in sensuous research. For instance, by getting respondents to use a digital camera and conducting a 'home-tour' with the author, audio-visual media evokes physical experiences together with sensorial experiences where all the senses simultaneously perceive images and/or metaphors. The involvement of the body of the field worker together with these sensory exposures translates into sensuous portraits of social life. Non-textual outlets for translating the senses may also be found in ethno-drama, other performance and audio technologies towards presenting sensual ethnography. Inquiry into domains such as sociology of body, emotions and visual sociology provides insights and contributes to theory, method and epistemology in the social sciences and beyond, broadening the field of sensory studies within and between cultures (Low 2012:276-279).

From these assertions, we can infer that the knowledge embedded in the aesthetic knowledge domain is a transaction between the experience of the observer-participant, the unbridled creative imagination of the artist, the cultural context of both the creator and the creation, and also the scientific judgement of the observer-participant. Discovering knowledge in the aesthetic knowledge domain means observing artful expressions from different vantage points, with self-reflection of an observer's position in relation to the art form and the context as a foothold from which boundaries can be crossed to participate in events. Knowledge embedded in poetics can be accessed through the self-awareness and 
self-conscious bodily participation of all research participants, sensing what the sometimes many voices try to articulate. A knowledge dimension can be accessed through transdisciplinary methodology that involves an intellectual interpretation of what is experienced by the senses by critically reflecting together on the meaning of what is experienced, as well as seeking a synthesis of sensory feeling. However, horizons merge towards some understanding of violent conflict and what is needed for reconciliation if analysis, synthesis, complementary reflection and judgement of different observers from different vantage points, including the lived experiences of communities in conflict, become a whole. For effective learning from the aesthetic knowledge domain and poetics, an in-depth understanding of the cultural norms that inform the artistic impression is required, avoiding both the notions to apply universal rules or for imagination to distort observations. The result of this sensory interpretation of poetics opens the access of better understanding of issues that are difficult to articulate in popular language and to analyse from a positivist perspective. If this new understanding were applied, it would potentially create new pathways to reconciliation. However, a process of validating, mapping, acknowledging individual subjectivity and collective reflection is crucial to the sensory interpretation of poetics, without ever claiming that the process is scientific.

\section{Research methodology Participating in rituals as methods of data collection}

Auslander (2003:127) asserts that the flat view of a ritual and the notion that ritual could be best understood as mechanisms for promoting group solidarity must be abandoned. According to Wepener (2004:34-37), the symbols of ritual are not merely reflections or expressions of components of social structure; they are multi-levelled and capable of creatively effecting social change on all of these levels. To achieve this change, a research methodology is required to document rituals as part of a larger research design.

The whole ritual must be studied and documented, including words, deeds and every single piece of information that will add to the clarification of the meaning of the term 'ritual'. The complete sensory interplay is important. The researcher should take into account everything he or she sees, hears, smells, feels or tastes during the performance (Lukken 1999:135-138). Documentation will entail examining the completely enacted ritual within its multiple contexts, including cult and cultural milieu, continuity and change, from the data obtained from both primary and secondary sources. A detailed study of what actually happens during the rite itself will be followed by an analysis of what actually happened (Stringer 1989:511-512).

The research methodology should include the documentation of both the enactment and the appropriation of the ritual by the participants. Although the ritual is embedded within a larger cultural system, the immediate culture in which the rituals take place should be described (Barnard 2001). A preferred method is community engaged participatory research (CEPR), a methodology used for the study of community ownership and sustainability. It builds on the knowledge resources of the community as a partnership between research institutions and community members, shares the findings of knowledge with all relevant stakeholders and applies it to the benefit of the community (Lazarus et al. 2012).

\section{Storytelling as a method of data collection}

According to Berns (2016):

Stories are both universal and individual. They are our mannerisms and our beliefs, our choice of words and our dreams for the future. Most of all, stories shape the way we interact with the world around us and how we define our role in it. We find purpose and belonging through stories - as individuals, communities, and nations. (p. 4)

In an oral culture 'you know what you can recall'. An oral culture has no texts; to create texts, an interlocutor is needed and sustained thought is linked to communication. Experience is put into any words, transforming it a little without falsifying it. In primary oral cultures, some people have not been exposed to writing in any form, but are able to produce powerful and valuable verbal performance of high artistic and human value. Once writing took over the mind, this may no longer be possible. However, without writing, human consciousness cannot achieve its full potential. Orality is destined to and needs to produce written knowledge. When reflecting upon it, the nature of the story is important. If the narrator or orator recalls and shares a linear tale that spans generations and is a relevant history to an entire group or community, it is a chronicle. If the storyteller expresses anecdotal, folk tales, or personal experiences with metaphor, symbolism and ethics 'told by old women to groups of children huddled near the kitchen fire during the cold season, it is a story' (Turner 1980:148).

Smith (2007) describes how apparently bounded cultural entities dissolve their cultural separation through narrative and storytelling, enlightening similarities. Narrative storytelling as a method is able to soften apparently hardened identities and allow understanding and reconciliation between peoples.

Storytelling is therefore more than just another way of telling and abstraction. It can be a deeply affective process of locating, articulating and communicating personal lived experiences. It opens the way for innovative sensorial strategies that involves sensuous, participant scholarship by immersion in the subjectivities and fictionalised realities that 'ring true' encoding (especially in digital format using a camera), analysis and interpretation of digital stories, knowledge production and the construction of meaningful sharing experience as well as relationship building in the context of a reconciliation process. 


\section{The case of the San of southern Africa The San, the First People of southern Africa}

The San is part of the First People of southern Africa, whose origins can be traced to the 'Mitochondrial Eve' from whom (according to Oppenheimer 2004:40) all Africans originated. The largest group of San People currently reside in an underdeveloped village called Platfontein on the outskirts of Kimberley, the capital of the Northern Cape Province of South Africa. The San of Platfontein speak Kwedam and !Kun, which distinguish them from other groups. The next largest San group is the $\vdots$ Khomani of the southern Kalahari, who descended from several original San groups, including the $\| \mathrm{Ng}$ ! $\mathrm{u}$ who are close relatives of the !Xam who lived south and north of the !Gariep River, also in the Northern Cape Province of South Africa.

These communities were selected as the research population because most of the people living there still suffer from the consequences of genocide before and during colonialism, soldiers fighting as surrogates for belligerents during the so-called Cold War, apartheid and a current South African society characterised by race-related turmoil. Despite these misfortunes, there is rich and abundant knowledge, leadership, and a strong religious component in their culture. Most conflicts that occur are within a context of spiritual and material impoverishment that is characteristic of post-conflict communities in Africa (see https:/ /dspace.nwu.ac.za/handle/ 10394/13079 for more readings about the San communities in conflict and in search for reconciliation).

\section{Accessing the poetic knowledge of the San: Ritualistic poetics and storytelling}

In 2016, the Institute for Dispute Resolution in Africa (IDRA) launched a research project to access knowledge to discover knowledge on dispute resolution and reconciliation embedded in the poetics of the San. The first research venture was to access knowledge on reconciliation and storytelling in digitalised form by facilitating two digital storytelling workshops. The digital storytelling events demonstrate the rawness of experiencing poetic expressions and thus sensuous scholarship as a method. The next research activity took place near the small town of Andriesvale during the Kalahari Desert Festival, September 2016 (Ferguson 2016a), involving the close observation of female rites of passage performance and the San dancing rituals that celebrate and create a culture of reconciliation. This section explains how the San poetics were accessed and how the sensuous experience was interpreted.

\section{Accessing ritualistic knowledge}

One of the most recognised rituals of the San is the 'trance dance'. This is one of the most researched aspects of the San and thus requires cautious attentiveness regarding the validity of the findings. As we are arguing the aesthetic and subjective, entirely relevant, perspective in this article and because of the sacred and/or private nature of the trance dance, the researchers who have claimed to experience the dance cannot be regarded as claiming the entire truth. Our opinion is based on the fact that any claim about the culturally poetic (poetry from a specific culture), and specifically ritualistic, needs to be recognised consciously as a partial claim about a greater cosmology of belief and practice: partial experience, partial analyses and partial conclusions and/or findings.

According to published knowledge about the trance dance (Lewis-Williams \& Pearce 2004:83-85; Ouzman 2009:221) and the authors' interviews with the San religious leaders and shamans, the dance has certain characteristics and purposes. Spiritually potent people (e.g. shamans, healers and seers) lead the dance that is usually held at night after eating or fasting, depending on the particular intentions of the dance. Instruments such as rattles are used to make an atmosphere that raises the frequency (energies) of the space - 'People clap, dance, sing and talk to create a spiritually charged and socially cohesive atmosphere that launches shamans to the Spirit World'.

An interview with Pupa Jan Pieterse, a community elder, mediator and spiritual leader, revealed that dance is typically initiated to resolve a physical or social ill that needs to be healed in a multidimensional way. Ritual is, in most cases, a creative performance that works to envision the life world of individuals and communities. In ritualistic time-spaces, the participants create and recreate their past, present and futures (Ferguson 2016b).

The following quote is from one of the shamans who led the ritual trance dance among the San in the Kalahari:

'You must make sure your spirit is clean. And you begin with the traditional healing dance to make your spirit clean... to make your body healthy, to make your mind clean, and to be positive. If your mind is not clean, you have negative thoughts. So this is where the leaders start. With the dance... to make them right and clean... and through that dance, they get their messages on where and how to do their work. And through the dance they get the spiritual messages of the medicines, what they do and where they are. With the dance, they know how to heal the people and how the healing must be. With the dance they become the medicine people for the community.' (Interview with community elder, mediator and spiritual leader, 2016, see http://uir.unisa. ac.za/hdl.handle.net/10500/21543)

During the Kalahari Desert Festival 2016, raw data were obtained by researcher Kate Ferguson (Ferguson 2016a) observing the ritual, music and dance at the campsite, which she experienced as 'creative, adaptable, and inclusive and could therefore include those who are not rehearsed in the performance. It is a ritualistic experience rather than a rehearsed ritual'. Participation in the San Dispute Resolution Project allowed her to learn significantly about the custom of the San people and informed her capability as a researcher, to some extent to interpret ritual elements in collaboration with knowledge holders from the community. She describes her experience as follows (Ferguson 2016a): 
After a little while of this quiet transition period came the sound of drums, beating intentionally, rhythmically and consistently by what could be gauged from our tent (about eight to ten meters away from the Kraal ${ }^{1}$ where everybody was gathered) as one person drumming. The sounds, of what I later learnt were N!UU language expressions and songs, rose and pierced the night's comparative silence and dove into the centre of the crackling spirited fire that held the circle of a choir and dance group. ${ }^{2}$ Although we did not see the fire or any of this performance with the sense of our eyes, we saw the remains of a fire the next day and the visuals of the scene became impressions behind my closed eyes as we listened and sensed the scene in the Kraal. The sounds: clicks, and shrieks that flowed and descended into low rhythmic moments; elongated expressions of voice that was accompanied by the shakers that are attached to ankles of dancers; emulations of animal utterances like bird calls, antelope sounds, onomatopoeic expressions, guttural sounds. In some instances, they are not clearly identifiable sounds but it is clear that they are channelling something from some place inside or outside of themselves. There was dancing to the rhythm of vocals and vocals singing to the rhythm of feet pounding the red sand, creating a harmony between song and dance. (p. 2)

The most important element of the above extract is related to the point that Auslander (2003:127) made that 'ritual, in its full per formative flow, is not only many-levelled, laminated but also capable, under conditions of social change, of creative modifications on all or any of its levels'. Ritualistic time-spaces, and in some cases their public performance, are therefore not merely representations of a culture, but rather a concentrated moment of creativity, where social and spiritual 'modifications' can be made in each person and within the community at large. Rituals are malleable and open to the moulding of hearts and minds. It is thus vital to recognise, encourage and potentially integrate some elements of these creative ritualistic spaces into real community building and reconciliation efforts. In saying 'some elements', it is important to note that it is not necessarily possible or respectful to try to claim the entirety of a ritual as these are also sacred spaces that require a certain degree of distance from public and institutional proceedings.

The extract also demonstrates the intuition, sensitivities and sensibilities required to engage in sensuous scholarship. Along with heightened senses for deep observation of a context are an equally heightened awareness of the self and an honest declaration of the limitations of the researcher in experiencing and later analysing a context. In this case, the insight of the researcher into the lives of the San was limited to two years of interrupted collaborative work with members of the San communities, influenced by personal and professional experience of rituals, which are sufficient to make claims about insights into the ritualistic life of the San. It was found that preliminary analysis occurs naturally,

\section{An Afrikaans term for a gathering place.}

2.The term 'choir' fits with a more acceptable Western or Christian understanding of what they are doing, which could, in this context or scene, more aptly be described as a youth group or a community of people singing together. particularly if the researcher is in-cultured and inscribed self (i.e. instilled with cultures and essential and own formative experiences), as highlighted by Brady (1991:12). However, the researcher was fully aware that her observations had to be collectively validated involving the San participants. As an 'outsider' who does not share the culture, she had to rely on collaborators from the community to understand the traditional rituals. She was also conscious of the probability that the ritual might be an enactment aimed at the presence of researchers and other observers. However, the spontaneity of the enactment, linked to the awareness of the researcher that interpretation of rituals requires collective interpretation, mitigated the limitations of sensual scholarship.

By reflecting on the literature and together with community participants, we infer that multidimensional, bonded and creative ritual has the potential for healing and reconciliation in the context of social change. Ritual is an immersive process where people have the opportunity to delve into themselves as individuals within a creative and supportive context. Ritual in a neutral setting potentially allows for intracommunity reconciliation of opposing groups when participants display trauma from different perspectives, involving a larger audience that can challenge individual bias without judgement. However, a ritual dance will not automatically make a person to accept the trauma or enable him or her to be totally healed. Healing is a long-term process that involves many aspects and not only the ritual. Furthermore, we acknowledge that the ritual is a difficult place to access from a structural functional vantage point. Not just anyone is welcomed into the intimate and delicate space of community-based ritual. The ritual is a creative, observable and poetic act that allows knowledge discovery, including knowledge required for reconciliation. Furthermore, the research demonstrated the richness and realness of engaging the poetic spheres of people and communities and thus the profound relevance of these dimensions to inform policy-making, decision-making and planning for communities experiencing and recovering from conflict situations.

\section{Theatrical storytelling}

In poetics, people will choose the issues or themes most relevant to them to work with as creative material. The performance at the Kalahari Desert Festival, called 'Die Hook', did just that. The descriptions of the poetic event at the festival demonstrate how communities, and particularly women, are striving towards reparations, recreations and reconciliation of gender dynamics and a revival and recreation of respect for both men and women. There is also a plight among the older generations that the younger generations are forgetting and do not care for the old stories that are passed down from generation to generation and regarded as ancient and sacred by the elders (Ferguson 2016b)). This theatre performance revisits, revives and re-imagines some old stories that connect the earth with the greater cosmos through the presence of the sacred fire and the moon figure. 
The following raw data were obtained from a theatre performance during the Kalahari Desert Festival that focused on the female experience in the San communities (Ferguson 2016a):

- The Ouma (grandmother) began narrating a 20-min story about the rites of passage that the Bushmen women go through as they enter womanhood and prepare to become wives and mothers. During the old woman's story, a younger version of herself stayed concealed behind a screen where the shadow of herself was acting out her reflections and descriptions of her early womanhood. The story described her being kept in a kind of solitary confinement where food and water was brought to her and how she spent her time sleeping and dreaming about a life outside of that space. Her mother would come and wash her down, scrub her skin until she was bleeding from being washed. This was the ritual cleansing that prepared her for her 'coming out' moment where she would sing and dance and be honoured for her womanhood and all that came along with that. When she emerged all decorated and cleansed, she danced around the fire under the moonlight to traditional music including drums and voice.

- The audience responded in different ways, with the majority clapping enthusiastically for the very simple and powerful story and how it was performed. A couple of young men under the influence of alcohol whistled, jostled and became rowdy when the young woman emerged from the confined part of her rite of passage. This immature masculine demonstration enlightened the need for such a story to be told about the traditional and sacred ways that women were supported and encouraged by their communities.

From the above story the researcher discovered the following data elements: female rites of passage; the moon symbol (cosmology); performative; storytelling; voice and body reflection; fire and water (cleansing); solitary confinement; matriarchal relations; ritual cleansing; dance during the pinnacle point of the rite of passage ritual; reflection of the moon, the shadow and the story (see Figure 1).

The illustration serves as a framework for interpretation of how reflective, mindful and sensitive practices of sensuous scholarship in poetic spaces may offer relevant and valuable insights into the breakdown of gender relations in the San communities. By observing the performance and using this framework, the researcher could detect elements of harmony and discord. Furthermore, the performance revealed the need for the reinstatement of rites of passage for both genders to

\begin{tabular}{|l|l|l|l|}
\hline \multirow{3}{*}{$\begin{array}{l}\text { Cultural } \\
\text { elements }\end{array}$} & Categories of concepts \\
\cline { 2 - 4 } & Ritual & Reconciliation & Gender \\
\cline { 2 - 4 } & Rhythm & Harmony of voices & Female rites of passage \\
\cline { 2 - 4 } & Moon & Discord of dance & Male rites of passage \\
\cline { 2 - 4 } & Washing & The end of the performance & $\begin{array}{l}\text { Male and female isolation and } \\
\text { reunion }\end{array}$ \\
\hline
\end{tabular}

Source: Illustration adapted from Bateson 1972:95

FIGURE 1: Ritual, reconciliation and gender in cultural context. alleviate generational amnesia on what is seen as disrespectful and immoral in gender relations in that specific cultural context leading to community conflicts.

\section{Digital storytelling}

Two digital storytelling workshops conducted with the San communities (November 2015 in Pretoria and June 2016 in Ashkam) highlighted the causal relationship between poverty, dispossession and conflict. During these workshops, each person chose the story they wanted to tell and they were prompted gently to link it to issues of law and justice. Each person shared a story about his or her experience of rising above the socio-economic context - 'the hero's journey'. For example, there was a story about a mother whose child had gone down the path of drugs and how difficult that was to overcome. Another person shared her experience of her mother dying from an illness. Another person was explicit about him 'coming from nothing' and then finding his gifts and his role in society. This is not to say that these experiences are exclusive to low-income and dispossessed people as drugs and illness occur in high-income communities. However, a particular context that is being overcome includes being low-income San communities in South Africa.

When considering the kinds of stories that are told, and how it relates to stories of peace and reconciliation, we can look at the digital story of Mario Mahongo (Ferguson/Mahongo, http://uir.unisa.ac.za/handle/10500/20559). He chronicles the movement of the !Xun and Khwe from the military base in Angola to the refugee camp next to the Orange River to the lands of the Platfontein Farm where they now live and have custodianship of the land. He entwines the hardships of dis- and translocation from their homelands in Angola to a country that has little capacity to treat the San and/or Bushmen communities as equal South African citizens. Mahongo also speaks in the first person about being a leader of his people who found and lost peace through lived experiences. There is an entwinement of chronicle and story in his expression.

In his storytelling, Mahongo employs a certain style where he speaks for himself and for his people as their leader. This is a mighty story that demonstrates that reconciliation is an ongoing journey with moments of peace and moments without peace. That Mahongo is the storyteller is powerful as he has walked the road and led his community through many stories of dislocation and location, conflict and harmony. That Mahongo decides to focus on building and raising Platfontein for the latter part of the story demonstrates his focus on redressing the past, reconciling that which is lost, creating, building and growing with the resources and abilities available.

\section{Reflections on the application of aesthetic knowledge for peace and reconciliation}

Knowledge from the aesthetic knowledge domain by means of transdisciplinary, participant observation of the poetics 
from a specific culture requires personal reconciliation, meaning that the researcher first goes through a process of self-reflection (as part of the methodology). The researcher needs to develop an honest awareness of how the cultural context of the creator of poetics differs from the context of the researcher, assuming that the researcher comes from another cultural context. Furthermore, the researcher has the challenge of differentiating between sensuous feeling and emotional involvement by sensing without constriction when participating in the event, but needs to re-establish emotional distance after the event in order to objectively evaluate and interpret what was experienced.

Once the researcher achieves this inner reconciliation, he or she can engage in participant scholarship following an innovative sensorial research strategy to access the knowledge in the aesthetic knowledge domain. Such a strategy will be launched from a vantage point where artful expressions can be accessed. A suitable course of action for the researcher will be to respond to poetic forms such as ritual, song, dance and storytelling as a whole person who embroiled themselves physically in the form to discover new knowledge. Such a response involves the assumption of responsibility by the researcher to enter into dialogue with the creator of the poetic form to share insights that could creatively add to the process of reconciliation. In applying this strategy, the researcher is purely an observer of processes and listener of stories, while becoming involved in the process of analysing and interpreting the meaning of such poetic expressions.

This per-action of sensuous participation and intellectual interpretation contributes to the understanding of the cultural norms of those who are in the process of reconciliation, which would otherwise be difficult to articulate in popular language. New perspectives can therefore be discovered from various forms of poetics when the communication of the creator aims at the creation or restoration of cultural identity, peaceful relations and connections among people towards reconciliation.

\section{Conclusions}

This article departed from the aim to evaluate poetics as a source of information to find practical solutions for reconciliation and peace-building in a community. The argument is forwarded that if access to the poetic forms of relatively peaceful communities is discovered, interpreted and understood, it will reveal how relationships are reconciled. This argument is supported by offering a conceptual framework on reconciliation, the aesthetic knowledge domain and poetics, making it relevant to peace and reconciliation. A transdisciplinary, participatory and engaged research methodology is discussed. Finally, an evaluation of specific forms of poetics researched with the San communities of South Africa to accomplish reconciliation is presented.

It was found that the poetic spaces of the ritual are open to creative imaginings and abilities if a community aspires for true and deep reconciliation. It is less about the exact nature of a specific ritual and more about the innovative characteristics of ritualistic spaces in general. It was also found that the poetic worlds of communities hold some of the most important knowledge for consideration regarding issues of conflict and reconciliation. From this knowledge, new perspectives could be discovered in a hermeneutic fashion by applying sensuous participation and intellectual interpretation. Interpretation requires that the researcher and the creator of the poetic form successfully merge their understandings of phenomena.

The merging of insights would require a research strategy that moves the vantage point of the researcher to become as intimate as possible with the artful expressions in order to sense meaning beyond popular language expressions. This would require inner reconciliation by the researcher and an awareness of the cultural context of the creator of poetic form. Furthermore, it would require on the part of the researcher to sense initially what is being articulated and then place some emotional distance to assert meaning from a neutral vantage point to ensure good scholarship. The knowledge that emerges from this mutual experience, if applied to the process of reconciliation in a community, may become creative, innovative and restorative.

\section{Recommendations}

It is proposed that all field researchers who engage in participatory research together with communities should develop an awareness that a wealth of knowledge is embedded in the aesthetic knowledge domain. The knowledge of differing cultural contexts, the skills to engage with many forms of poetics and a mindset that enables research beyond disciplinary boundaries should be an important venture to develop researchers.

From the perspective of the community artist, it is important that the creative energy and the quest to influence positive change through all forms of artistic expression should never be abandoned. Creativity is not to be drowned out by dominant narratives from scholarly and other interpretations that failed to dwell beyond scientism to a dimension where metaphysical knowledge can be applied to find reconciliation.

Policymakers should take cognisance of messages from communities articulated through art form such as storytelling and ritual, especially where the articulation of needs and expectations are limited by the use of unique language. Especially people involved in formulating and implementing peace and reconciliation strategies may derive valuable information from observing and participating in rituals, or simply listening to stories told. Specifically, in the case of dispute resolution, storytelling and ritual can form an important part of the process for identifying the cause, understanding the dynamics and dealing with the consequences of disputes. In the case of storytelling, it can serve the purpose of fact-finding in customary law as well as during modern court proceedings. In the case of ritual, it forms an important part of cleansing and healing in African communities after violent conflict. It is therefore of vital importance that the art and science of researching poetics and knowledge production from the aesthetic knowledge 
domain find their way into learning contents and curricula in all educational dimensions.

\section{Acknowledgements}

The authors would like to thank the San, the First People of southern Africa, especially the communities of Platfontein, Andriesvale, Welkom, Rietfontein and Philandersbron, for participating in the study.

The authors declare that only professional and intellectual considerations as researchers inspired them to write this article. Declarations of Interest were signed by both authors to comply with University of South Africa (UNISA) policy requirements before the start of the project.

This research was financially supported by the College of Law, University of South Africa, and the National Research Foundation of South Africa. The views expressed in the article are those of the researchers and authors and does necessarily represent the funders' views.

\section{Competing interests}

The authors declare that they have no financial or personal relationships which may have inappropriately influenced them in writing this article.

\section{Authors' contributions}

A.G.V. was the project manager and responsible for writing of the conceptual framework, interpretation of data, findings and overall quality control. K.D.F. was a junior researcher who led the field research and wrote the original field research reports, the research report part of the article, performed critical reading and contributed to interpretations and findings.

\section{References}

Auslander, P., 2003, Performance: Critical concepts in literary and cultural studies, Routledge Taylor and Francis Group, London.

Barnard, M. 2001, 'Dynamiek van cultus en cultuur' (Dynamics of cult and culture), in M Barnard \& P Post (eds.) Ritueel bestek. antropologische kernwoorden van de liturgie geredigeerd, Zoetermeer: Meinema.

Bateson, G., 1972, Steps to an ecology of mind: Collected essays in anthropology, psychiatry, evolution, and epistemology, Chandler Pub. Co., San Francisco, CA.

Berns, J., 2016, Letter from the Editor-In-Chief: Inside the storytelling revolution. Building peace: $A$ forum for peace and security in the 21st century, Alliance for Peacebuilding, Washington, DC.

Brady, I., 1991, 'Harmony and argument: Bringing forth the artful science', in I. Brady (ed.), Anthropological poetics, pp. 3-30, Rowman and Littlefield, Maryland.

Brady, I., 2003, The time at Darwin's Reef: Poetic explorations in anthropology and history, AltaMira, Walnut Creek, CA.

Burke, E., 1958, 'Introduction' in J.T. Boulton (ed.), A philosophical enquiry into the origin of our ideas of the sublime and beautiful, pp. 26-27, Routledge \& Kegan Paul, London.

Butcher, S.H., 1992, Aristotle poetics, MacMillan, London.
Cohen, C.E., 1997, 'A poetics of reconciliation: The aesthetic mediation of conflict' Dissertation submitted to the University of New Hampshire in partial fulfillment of the requirements for the Degree of Doctor of Philosophy in Reading and Writing the requirements for the Degree of Doctor
Instruction University of New Hampshire.

Cohen, C.E., 2005, Creative approaches to reconciliation, Brandeis University, Waltham, MA.

Cohen, C.E. \& Yalen, L., 2005, Peacebuilding and the arts. Recasting reconciliation through culture and the arts, The International Center for Ethics, Justice, and Public Life, Brandeis University, Waltham, MA

Dervin, B., 1992, 'From, the minds eye of the user, The Sense-Making QualitativeQuantitative Methodology', in B. Dervin \& L. Foreman-Wernet (eds.), Sense-making methodology reader 2003, pp. 61-84, Hampton Press, New York.

Dervin, B., 2011, Connecting with specific publics: Treating communication communicatively, Eastern Spotlight: Brenda Dervin, Lecture at Les Schwab Room the Spokane Arena, viewed 01 September 2017, from http://www.youtube.com/ watch?v=foyH6eolseQ

Eaton, M., 2016, Aesthetic concepts, viewed 01 September 2017, from https://www. rep.routledge.com/articles/aesthetic-concepts/aesthetic-concepts-as-contextualconstructs

Ferguson, K.D., 2016a, Kalahari Desert festival report, viewed 15 June 2017, from http://hdl.handle.net/10500/21786 (SANDROA).

Ferguson, K.D., 2016b, Andriesvale interview with Oupa Jan (community elder, mediator and spiritual leader, viewed 15 June 2017, from http://hdl.handle.net/10500/ 21543 (SANDROA).

Gadamer, H.-G., 1976, Philosophical heremeneutics, University of California Press, Berkeley, CA.

Habermas, J, 2003, The future of human nature, Polity Press, Cambridge, pp. 35-38.

Heidegger, M., 1927 [1962], Being and time, Harper, New York. (Original work published 1927).

Komesaroff, P., 2008, 'Pathways to reconciliation: Bringing diverse voices into conversation', in P. Rothfield, C. Flemming \& P.A. Komesaroff (eds.), Pathway to reconciliation, pp. 1-12, Ashgate Publishing Company, Aldershot.

Lewis-Williams, D. \& Pearce, G., 2004, San spirituality: Roots, expression, and socia consequences, Juta, Cape Town.

Lazarus, S., Duran, B., Caldwell, L. \& Bulbulia, S., 2012, 'Public health research and action: Reflections on challenges and possibilities of community-based participatory research', in J. Maddock (ed.), Public Health, viewed 01 September 2017, from http://www.intechweb.org

Longe, W.J. \& Brecke, P., 2003, War and reconciliation: Reason and emotion in conflict, MIT Press, Cambridge, MA.

Low, K.E.Y., 2012, The social life of the senses: Charting directions. Sociology compass $6 / 3$, Blackwell Publishing, Singapore.

Lukken, G., 1999, Rituelen in overvloed. Een kritische bezinning op de plaats en de gestalte van het christelijke ritueel in onze cultuur, Gooi \& Sticht, Baarn.

Mcniff, S., 2008, 'Artbased Research', in J.G. Knowles \& A.L. Cole (eds.), Handbook of the arts in qualitative research: Perspectives, methodologies, examples and issues, pp. 29-40, Sage, Thousand Oaks, CA

Nicolescu, B., 2005, 'Towards transdisciplinary education and learning', Paper prepared for conference on 'Science and Religion: Global Perspectives', Metanexus Institute, Philadelphia, PA, 04-08 June, viewed 01 June 2015, from http://www. metanexus.net

Oppenheimer, S. 2004. Out of Africa's Eden. The peopling of the world. Johannesburg, Jonathan Ball.

Ouzman, S., 2009, 'San cosmology', in H. Selin (ed.), Encyclopaedia of the history of science, technology, and medicine in Non-Western cultures, pp. 219-225, Springer, New York.

Russel, B., 2013, 'The place of science in a liberal education', The Collected Papers of Bertrand Russell 12, 390-397.

Smith, T., 2007, 'Narrative boundaries and the dynamics of ethnic conflict and conciliation', POETICS: Journal of Empirical Research on Culture, the Media and the Arts 35, 22-46.

Stoller, P., 2012, Sensuous scholarship, University of Pennsylvania Press, Philadelphia, PA.

Stringer, M.D., 1989, 'Liturgy and anthropology: The history of a relationship', Worship 63(6), 503-521.

Turner, V., 1980, Social dramas and stories about them. Critical inquiry, The University of Chicago Press, Chicago, IL.

Tutu, D.M., 2000, No future without forgiveness, Image Books, New York.

Velthuizen, A.G., 2016, 'The quest for Great Heart Leadership to activate and promote the ending of violent conflict in Africa', African Journal on Conflict Resolution 16(1), 61-86.

Wepener, C.J., 2004, 'Van vas tot fees. 'n Ritueel-liturgiese ondersoek na versoening binne Suid-Afrikaanse kultuurkontekste', DTh thesis, University of Stellenbosch. 